\title{
Parallel changes in gene expression in peripheral blood mononuclear cells and the brain after maternal separation in the
} mouse

\author{
Johan H van Heerden ${ }^{1}$, Ana Conesa ${ }^{2}$, Dan J Stein ${ }^{3}$, David Montaner ${ }^{2}$, \\ Vivienne Russell ${ }^{4}$ and Nicola Illing*1
}

Address: ${ }^{1}$ Department of Molecular and Cell Biology, University of Cape Town, Rondebosch, 7701 . South Africa, ${ }^{2}$ Bioinformatics Department, Centro de Investigación Principe Felipe, Valencia, Spain, ${ }^{3}$ Department of Psychiatry, University of Cape Town, Rondebosch, 7701, South Africa and ${ }^{4}$ Department of Human Biology, University of Cape Town, Rondebosch, 7701, South Africa

Email: Johan H van Heerden - jheerd@falw.vu.nl; Ana Conesa - aconesa@cipf.es; Dan J Stein - dan.stein@uct.ac.za;

David Montaner - dmontaner@cipf.es; Vivienne Russell - vivienne.russell@uct.ac.za; Nicola Illing* - nicola.illing@uct.ac.za

* Corresponding author

Published: 25 September 2009

BMC Research Notes 2009, 2:195 doi:10.1186/1756-0500-2-195
Received: 3 August 2009

Accepted: 25 September 2009

This article is available from: http://www.biomedcentral.com/1756-0500/2/195

(C) 2009 Illing et al; licensee BioMed Central Ltd.

This is an Open Access article distributed under the terms of the Creative Commons Attribution License (http://creativecommons.org/licenses/by/2.0), which permits unrestricted use, distribution, and reproduction in any medium, provided the original work is properly cited.

\begin{abstract}
Background: The functional integration of the neuro-, endocrine- and immune-systems suggests that the transcriptome of white blood cells may reflect neuropsychiatric states, and be used as a non-invasive diagnostic indicator. We used a mouse maternal separation model, a paradigm of early adversity, to test the hypothesis that transcriptional changes in peripheral blood mononuclear cells (PBMCs) are paralleled by specific gene expression changes in prefrontal cortex (PFC), hippocampus (Hic) and hypothalamus (Hyp). Furthermore, we evaluated whether gene expression profiles of PBMCs could be used to predict the separation status of individual animals.

Findings: Microarray gene expression profiles of all three brain regions provided substantial evidence of stress-related neural differences between maternally separated and control animals. For example, changes in expression of genes involved in the glutamatergic and GABAergic systems were identified in the PFC and Hic, supporting a stress-related hyperglutamatergic state within the separated group. The expression of 50 genes selected from the PBMC microarray data provided sufficient information to predict treatment classes with $95 \%$ accuracy. Importantly, stress-related transcriptome differences in PBMC populations were paralleled by stress-related gene expression changes in CNS target tissues.

Conclusion: These results confirm that the transcriptional profiles of peripheral immune tissues occur in parallel to changes in the brain and contain sufficient information for the efficient diagnostic prediction of stress-related neural states in mice. Future studies will need to evaluate the relevance of the predictor set of 50 genes within clinical settings, specifically within a context of stress-related disorders.
\end{abstract}




\section{Background}

The application of microarray techniques has provided insights into the multi-dimensional molecular nature of complex neuropsychiatric disorders. Studies have highlighted the value of using peripheral tissue targets $[1,2]$, an approach based on the functional integration of neural-, endocrine- and immune-systems [3]. Regulatory exchanges between components of these systems provide a foundation for using peripheral tissue targets as indicators of neuropsychiatric states.

One of the earliest demonstrations that gene expression changes in peripheral blood mononucleoctyes (PBMCs) reflected disease states in the brain, was based on a rat model, where acute neural assaults resulted in gene expression changes in PBMCs within 24 hours [4]. Recent studies have focused on human neuropsychiatric disorders with more subtle disruptions in neurophysiology. Segman et al [1] were able to predict the onset and progression of post-traumatic stress disorder (PTSD), in recently traumatised patients. Similarly, Tsuang et al [2] showed that the microarray analysis of peripheral blood samples discriminated between patients clinically diagnosed with schizophrenia or bipolar disorder and healthy controls. Nevertheless, it remains to be established whether gene expression changes in peripheral tissue targets are paralleled by specific transcriptional alterations in neural tissues [1].

We have used the model of maternal separation, which is known to induce long term alterations in neurophysiology and stress-related behaviours in adult rodents $[5,6]$ to investigate i) whether parallel changes occur in gene expression in three brain regions (the prefrontal cortex, hippocampus, and hypothalamus) and PBMCs and ii) whether gene expression changes in PBMCs could be used to predict the animal treatment group.

\section{Methods}

\section{Animals and treatment}

Maternal separation was carried out on C57BL/6 mice as previously described [6] with some modifications. Briefly, MS litters were separated from dams for $3 \mathrm{~h}$ a day, starting at $12 \mathrm{~h} 00$ and ending at $15 \mathrm{~h} 00$, from postnatal day (PND) 1 to 14 . SH animals underwent brief daily handling. All subsequent procedures were carried out using males only, as the consequences of separation are gender specific [6].

\section{Acute restraint stress, sacrifice, blood collection and brain dissections}

Mice $\left(\mathrm{N}_{\mathrm{MS}}=30, \mathrm{~N}_{\mathrm{SH}}=30\right)$ were subjected to $10 \mathrm{~min}$ of acute restraint stress and allowed to recover for $20 \mathrm{~min}$ prior to sacrifice. Restraint stress was chosen as a means of acutely activating the Hypothalamic-Pituitary-Adrenal
(HPA) axis (HPAA), which allowed for an assessment of possible differences in plasma corticosterone profiles (van Heerden et al, submitted manuscript). All mice were sacrificed, by means of cervical dislocation, immediately followed by decapitation and collection of trunk blood. Neural tissues: the (1) prefrontal cortex (PFC), (2) hippocampus (Hic) and (3) hypothalamus (HYP) were immediately dissected and submerged in RNALater ${ }^{\circledR}$ (Qiagen Inc., USA).

\section{Microarray processing and data analysis}

Fifty-five samples, $15 \times$ PFC $(8 \times$ MS and $7 \times$ SH $), 10 \times$ Hic and $10 \times$ Hyp $(5 \times$ MS and $5 \times$ SH, each and $20 \times$ PBMC $(10 \times$ MS and $10 \times \mathrm{SH})$ were used for microarray processing, with a two-colour common reference design. Samples were matched, so that 10 individuals $(5 \times \mathrm{MS}$ and $5 \times \mathrm{SH})$ were completely represented in all tissues. A common reference pool was constructed by combining equal amounts $(0.75 \mu \mathrm{g})$ of PFC and Hic RNA from both groups. Commercial pre-spotted, full mouse genome, microarray slides $\left(\right.$ OpArray $\left.{ }^{\mathrm{TM}}\right)$ were sourced from Operon (Operon Biotechnologies, Germany). Full details of RNA labelling, microarray hybridization, image capture and microarray data processing are given in Additional file 1: Supplementary Methods. Microarray data are available in the ArrayExpress database http://www.ebi.ac.uk/arrayexpress under accession number E-MEXP-2101.

Data normalization was done in $\mathrm{R}$, using the Limma package [7]. Pre-processing and removal of batch effects were done using GEPAS http://www.gepas.org and ASCA-genes [8] respectively. Differentially expressed genes were identified using a concordance strategy [9], based on overlap between three statistically divergent approaches. Genes that had a P-value < 0.05, using both the Info statistic, from the ScoreGenes software package http:// www.cs.huji.ac.il/labs/compbio/scoregenes/, and the Tusher et al [10] Significance Analysis of Microarrays (SAM) implementation in the T-Rex module of GEPAS http://www.gepas.org, in addition to an absolute foldchange $>1.2$ (where fold change is defined as the fold difference between MS and SH), were considered to be differentially expressed (DE).

All data clustering was done in the Tigr MultiExperiment Viewer V4.1 (TMEV, http://www.tm4.org) using a Pearson correlation metric with average linkage. Functional enrichment of GO terms within differentially expressed gene sets was evaluated using Blast2GO [11]. Gene set enrichment analysis on lists ordered according to SAM statistics was done using FatiScan http://www.babe lomics.org[12]. The PFC and Hyp lists were evaluated using 50 partitions, the PBMC list using 55 partitions and the Hic list using 60 partitions. 
The efficiency of PBMC gene expression profiles at predicting the treatment class of samples (i.e. $\mathrm{MS}$ or $\mathrm{SH}$ ) was evaluated with the Prophet module in GEPAS http:// www.gepas.org[13] using both the K-nearest neighbour (KNN) and Support Vector machine (SVM) algorithm options. Leave-one-out cross validation was used to counter selection bias whilst simultaneously assessing prediction efficacy.

\section{Results and Discussion}

Microarray data comparing the response of control and MS adult mice to stress was used to investigate the presence of a functional link between gene expression changes in the brain and PBMCs. In the first instance data was analysed to characterise the transcriptional response of three brain regions, the prefrontal cortex, the hippocampus and hypothalamus to stress, and to investigate whether a coordinated change in glutamatergic and GABAergic systems occurred in MS mice. Corresponding differences in gene expression in PBMCs of MS mice compared to control mice were also identified. Importantly, these differences could be used to predict the treatment status of mice.

\section{Microarray analysis}

After normalization, replicate merging, removal of flagged features and imputation, the number of genes expressed in each tissue was: (1) PFC, 15 760; (2) Hic, 17 344; (3) Hyp, 15794 and (4) PBMC, 13306.

\section{MS produced gene expression differences in all tissues}

Differentially expressed (DE) genes were identified in all tissues (Figure 1A-D). A summary of all DE genes is provided in [see Additional file 2 Table S2], [see Additional file 3 Table S3], [see Additional file 4 Table S4], and [see Additional file 5 Table S5]. The unsupervised hierarchical sample clustering of differentially expressed genes, produced clear group (MS or SH) separations within all tissues (Figure 1E-H). No single gene was differentially expressed across all tissues.

\section{Gene set enrichment analysis revealed significant functional themes}

The FatiScan analysis revealed the significant enrichment of functional terms, in all tissues (Figure 2 and Figure 3 ). In PBMC samples (Figure 3B), over-expressed terms could be grouped, generally, into signalling- (GO:0004872, GO:0051606, GO:0005887, GO:0007165, GO:0007154), immune- (GO:0006955, GO:0006952, GO:0005856, GO:0007275) and, interestingly, neurologically-related (GO:0008188, GO:0050877) classes. On the other hand, under-expressed terms all displayed a metabolic theme, with terms related to RNA and protein processing (GO:0003735, GO:0016070, GO:0044267, GO:0009058, GO:0009059, GO:0015031, GO:0006412, GO:0005840, GO:0003676 and GO:0043021) and energy metabolism (GO:0005739, GO:0051187 and GO:0006099). These results suggest a functional shift in the immune system in PBMCs in MS mice, characterised by the coordinated down-regulation of energy requiring processes, such as protein synthesis and transport. This functional shift might reflect the well characterised mobilisation of energy and inhibition of further storage in response to stress [14].

\section{Response of the glutamergic and GABergic systems in neural tissues after stress}

DE genes and enriched functional terms from the PFC datasets highlighted the importance of the glutamatergic and GABAergic systems in the stress-related response of the MS mice. These two neurotransmitter systems constitute the major stimulatory (glutamate) and inhibitory (GABA) mechanisms of neurotransmission, and work counteractively to ensure optimal neuronal activity after stress [15]. Glutamatergic signalling was enhanced in MS mice possibly as a consequence of deficiencies in GABAergic mediated inhibitory mechanisms.

DE genes whose products are involved in the modulation of glutamatergic and GABAergic signalling included P2yr4 and $N p v f$ (Figure 4). The activation of $\mathrm{P} 2 \mathrm{yr} 4$ positively regulates glutamate release [16], whereas Npvf is an important inhibitor of GABAergic neurotransmission [17]. The over-expression of both these genes in the MS PFC tissue, points to a hyperactive glutamatergic system. Supporting this observation is the under-expression of Myo6 in the MS samples. Myo6 is crucial for the efficient endocytosis of postsynaptic glutamate receptors, with deficiencies resulting in increased excitatory neurotransmission [18]. Htr3a was also under-expressed in MS samples. This receptor is strongly associated with GABAergic neurons and interneurons which activate the GABA mediated inhibitory neurotransmission in the prefrontal cortex [19]. The coordinated under-expression of both pre- and post-synaptic component GO terms further supports the hypothesis of a hyperglutamatergic state in the PFC of MS mice (Figure 4). Specifically, genes supporting depletion of postsynaptic components in MS mice included three $\mathrm{GABA}_{\mathrm{A}}$ receptors $\left(\mathrm{GABA}_{\mathrm{A}}\right.$ alpha- 1 and -3 , and $\mathrm{GABA}_{\mathrm{A}}$ gamma-3) (Figure 4); such receptors mediate inhibition of neurotransmission with disruptions resulting in enhanced anxiety [20]. Genes supporting functional depletion of presynaptic components included two metabotropic glutamate receptors, $m G l u R 3$ and $m G l u R 7$ (Figure 4). These receptors participate in negative feedback mechanisms that inhibit presynaptic glutamate release. Results from the hippocampal gene expression dataset extend these observations, with the over-representation, in MS samples, of genes involved in ionotropic glutamate signalling (Figure 4). Although this hyperglutamatergic theme was not readily apparent in either the DE genes or func- 

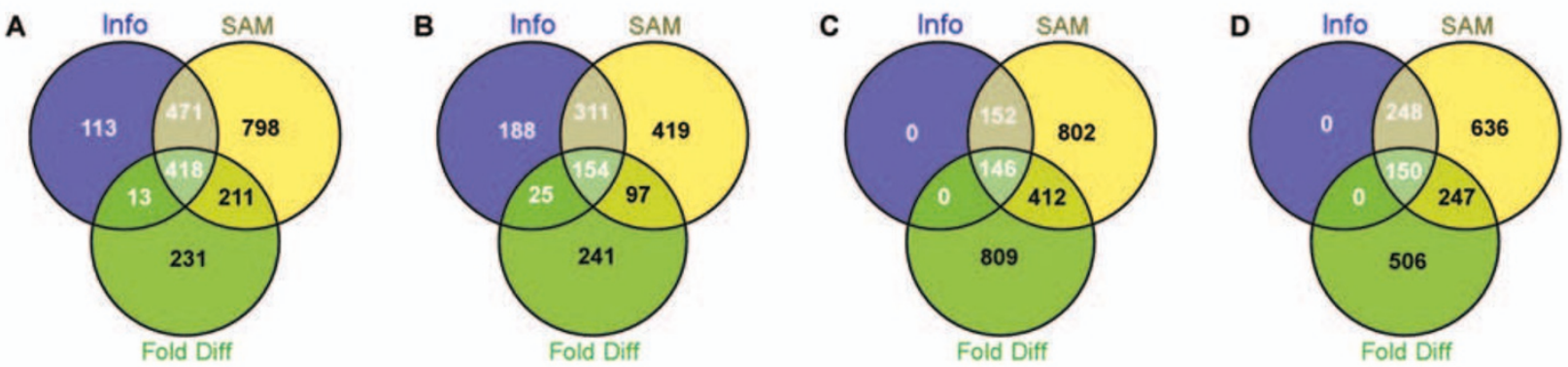

E
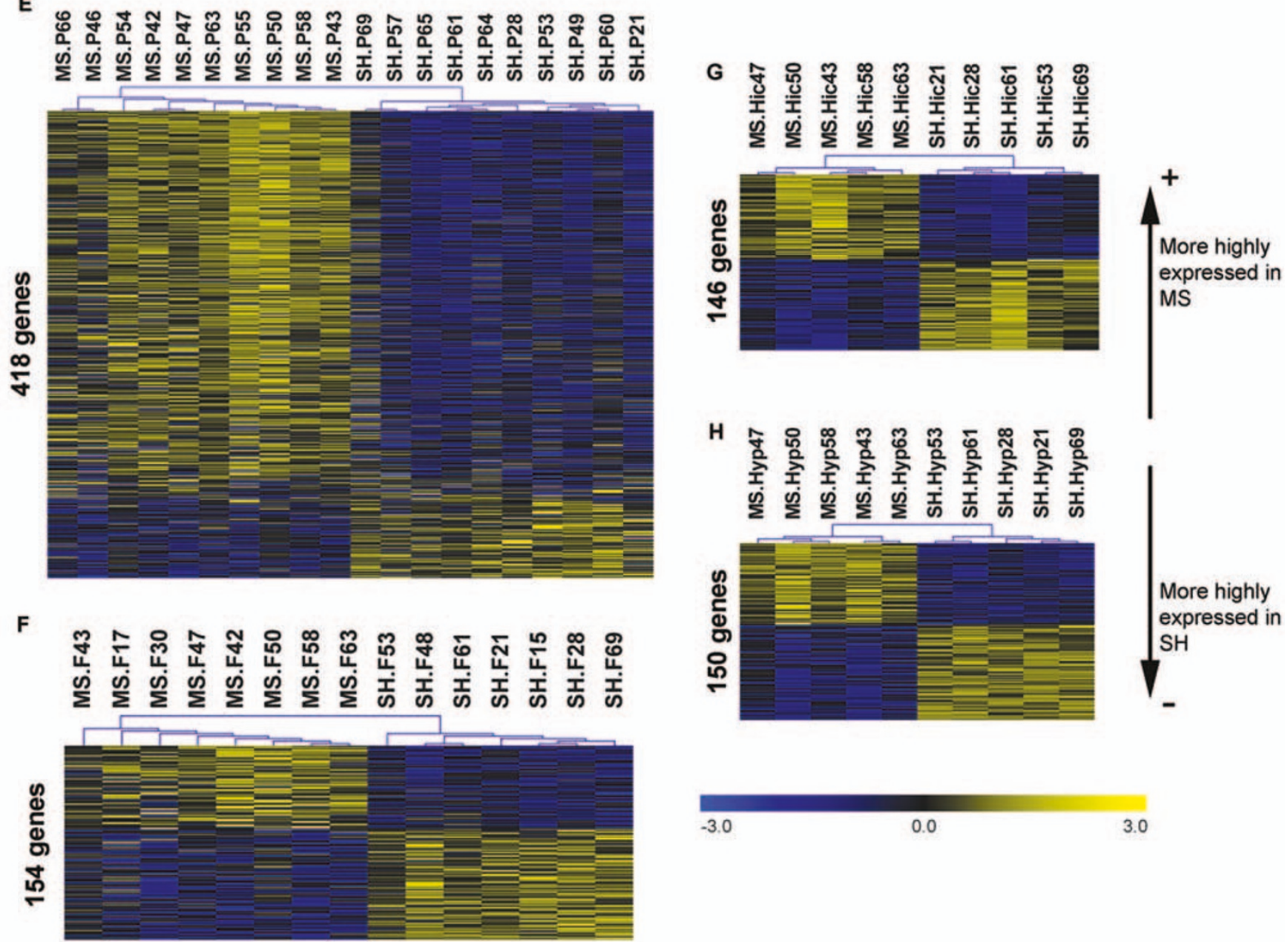

Figure I

Differential gene expression results. Venn diagrams show the overlap between different gene selection criteria (Info and SAM P < 0.05 and Fold difference > I.2) for (A) PBMC, (B) PFC, (C) Hic and (D) Hyp. This gene selection strategy significantly reduced the number of genes identified as DE by any one single criterion. Also shown are the false colour sample profiles of hierarchically clustered differentially expressed genes for (E) PBMC samples [347 over- and 7I under-expressed], and neural tissues (F) pFC [66 over- and 88 under-expressed], (G) Hic [7I over- and 75 under-expressed] and (H) Hyp [69 over- and $8 \mathrm{I}$ under-expressed]. The selected genes produce a clear separation between MS and SH samples. Genes more highly expressed in MS samples are at the top and those more highly expressed in SH samples at the bottom. $\mathrm{P}=\mathrm{PBMC} ; \mathrm{F}=\mathrm{pFC}$. 


$\begin{array}{ccc}\text { OVER-Represented } & \text { MS } & \text { UNDER-Represented } \\ \text { UNDER-Represented } & & \text { OVER-Represented }\end{array}$

\begin{tabular}{|c|c|c|c|c|c|c|c|c|c|c|c|}
\hline \multirow{2}{*}{ A } & \multicolumn{4}{|c|}{ \% of annotated genes } & & \multirow{2}{*}{ B } & \multirow{3}{*}{\multicolumn{4}{|c|}{ \% of annotated genes }} & \\
\hline & 20 & 40 & 60 & 80 & 100 & & & & & & \\
\hline cholesterol biosynthetic process & & & & & | G0:0006695 & & & & & & \\
\hline structural constituent of ribosome & & & & & GO:0003735 & 0 & 20 & 40 & 60 & 80 & 100 \\
\hline G-protein coupled receptor activity & & & 1 & & GO:0004930 & neuropeptide signalling pathway & & & & & GO:0007218 \\
\hline ribonucleoprotein complex & & & 1 & & G0:0030529 & steroid binding & & & & & G0:0005496 \\
\hline receptor activity & & & 1 & & 60:0004872 & behavioural defense response & & & & & | G0:0002209 \\
\hline cell surface receptor linked signal transduction & & & 1 & & G0:0007166 & fear response & & & & & | GO:0042596 \\
\hline GO:0008104 & & 1 & & & protein localization & ionotropic glutamate receptor activity & & & & & GO:0004970 \\
\hline GO:0006886 & & 1 & & & intracellular protein transp & hormone activity & & & & & GO:0005179 \\
\hline GO:0051234 & & 1 & & & establishment of localizati & postsynaptic membrane & & & & 1 & GO:0045211 \\
\hline GO:0008565 & & I & & & protein transporter activit & & & & & & \\
\hline GO:0045211 & 1 & & & & postsynaptic membrane & & & & & & \\
\hline GO:0042734 & 41 & & & & presynapticmembrane & & & & & & \\
\hline GO:0043190 & & & & & AIP-binding cassette (ABC) & r complex & & & & & \\
\hline
\end{tabular}

\section{Figure 2}

FatiScan gene set enrichment results. Shown are significant co-ordinately expressed GO terms within whole gene sets for (A) PFC and (B) Hic. The normalized percentage of genes annotated with a specific term is indicated for each group. Red indicates coordinated over-expression in MS group and Blue coordinated over-expression SH group (or under-expression in MS group). Colour intensity denotes how strongly a term is over- or under-expressed.

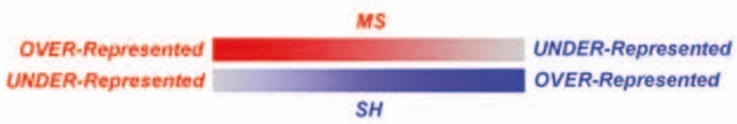

A

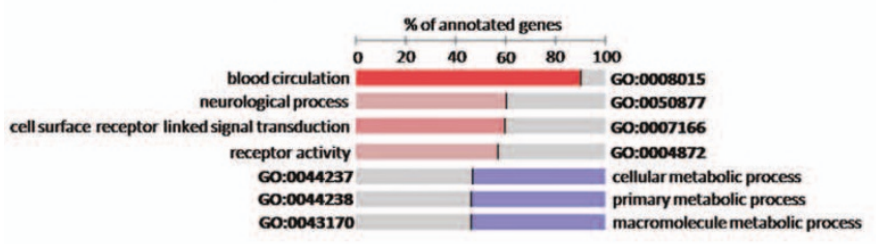

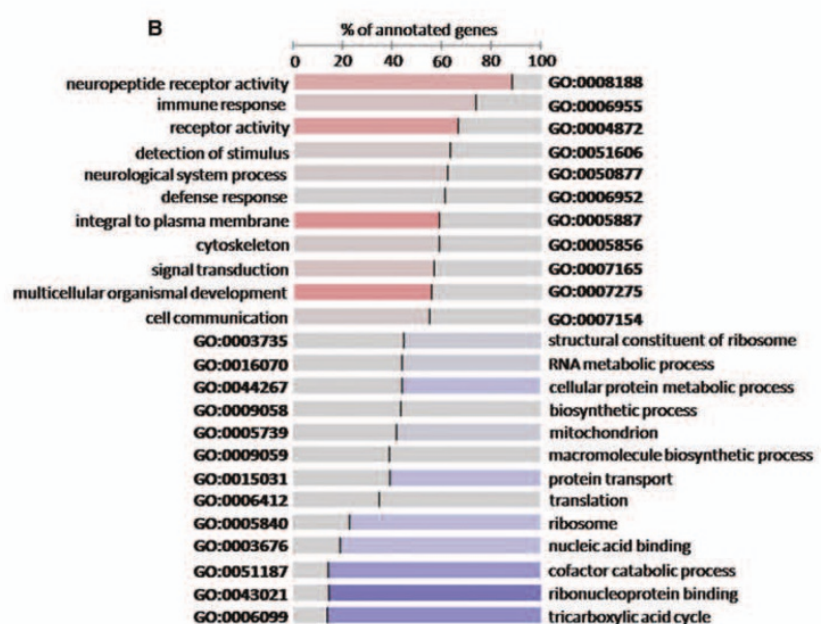

Figure 3

FatiScan gene set enrichment results. Shown are significant co-ordinately expressed GO terms within whole gene sets for (A) Hyp and (B) PBMC. The normalized percentage of genes annotated with a specific term is indicated for each group. Red indicates coordinated over-expression in MS group and Blue coordinated over-expression SH group (or under-expression in $\mathrm{MS}$ group). Colour intensity denotes how strongly a term is over- or under-expressed. 


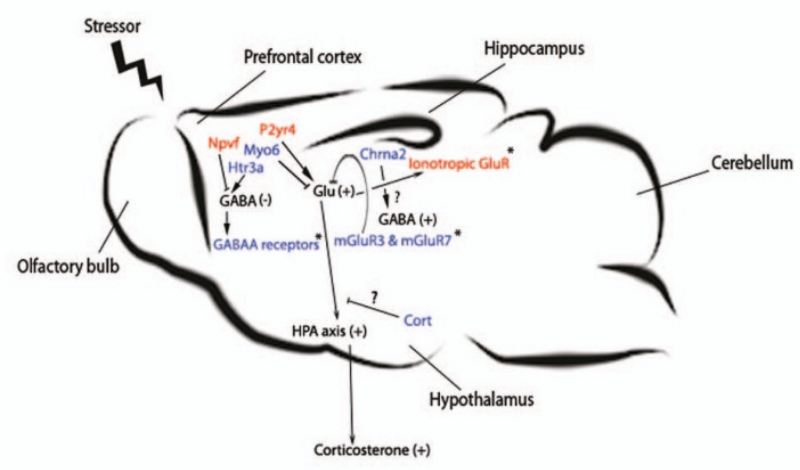

Figure 4

Schematic summary of neural gene expression results in support of a stress-related hyperglutamatergic state in MS brain samples. Such a hyperglutamaterigc state could potentially result in elevated stress-induced corticosterone responses. Red indicates over-expression and blue under-expression, in MS samples, respectively. An asterisk indicates genes or functional classes that were found to be regulated in a coordinated manner. Glu $=$ Glutamate, $(+)$ indicates increased signalling activity, $(-)$ indicates decreased signalling/acitivity.

tionally enriched terms of the hypothalamus dataset, under-expression of cortistatin may be relevant insofar as cortistatin signalling inhibits glutamate induced responses in hypothalamus [21] (Figure 4).

These findings are consistent with the central role of glutamate in the stress-response, in structures such as PFC and hippocampus. Stressors such as acute restraint have been shown to produce dramatic and rapid increases in glutamate levels primarily in the PFC, which ultimately culminates in HPAA activation and glucocorticoid secretion. In addition, the hippocampus is a major site of stress-associated glutamate action. The mechanisms which regulate glutamate action and release within this region function downstream of prefrontal cortical processes, constituting a secondary stress-response phase, which, unlike the PFC, is sensitive to neuroendocrine modulation [22]. The glutamatergic signature found here in both the PFC and hippocampus is therefore consistent with previous work.

\section{Functional significance of gene expression changes in PBMC tissues}

A large number of genes (418) were found to be differentially expressed between MS and SH individuals and included several genes whose products are important modulators of immune system function. Examples include Foxp3, an essential modulator of $\mathrm{T}$ cell function [23]; IL-17ra, the receptor target for the IL-17 mediated inflammatory pathway [24]; and Ccl5 (also known as
Rantes), which regulates the activity of several cellular populations within the immune system [25].

The evidence obtained from the neural transcriptomes (combined with corticosterone and behavioural profiles; van Heerden et al Submitted Manuscript) indicates that pre-weaning treatment (MS or $\mathrm{SH}$ ) result in differential stress-related profiles. Given this context, the gene expression information derived from the PBMC samples was evaluated in terms of its ability to derive accurate predictions of pre-weaning status of individuals.

\section{PBMC gene expression profiles accurately predict sample classes}

The classification and prediction of sample classes (MS or $\mathrm{SH}$ ) using PBMC gene expression values, were found to be highly efficient. Using KNN (with 4 neighbours), 50 genes (Figure 5; Table 1) were sufficient to accurately identify sample classes 19 out of 20 times. Most of the genes included in the predictor were over-expressed (Figure 5B). SVM, however, only achieved this success rate using a minimum of 125 genes (with linear and radial kernels). Importantly, this 125 gene set consisted of the 50 genes included in Table 1, in addition to 75 other genes, which were the same for both algorithms (data not shown).

Of the 50 genes included in the predictor, 46 were functionally annotated. Of particular interest was the identification of 3 genes, Oxt, Cck and Adcy8 (all over-expressed), whose products are known to be important mediators of stress- and anxiety-associated behaviours (Table 1) [2628]. Both Oxt and Cck are neuroactive hormones with previously described endogenous immunomodulatory properties $[29,30]$. These results confirm that the transcriptional profiles of peripheral immune tissues do indeed contain sufficient information for the efficient diagnostic prediction of stress-related neural states in mice. Products of these genes may participate in pathways that are particularly sensitive to stress-induced regulation of the immune system.

\section{Competing interests}

The authors declare that they have no competing interests.

\section{Authors' contributions}

JHvH carried out the animal studies, microarray experiments, data analysis and drafted the manuscript. NI designed and supervised the study, and assisted with the writing of the manuscript. DM and AC assisted with the analysis of the microarray data. DJS and VR contributed to the conception and design of the study, and assisted in the editing of the final versions of the manuscript. All the authors read and approved the final manuscript. 
Table I: Summary of 50 gene predictor set, which classified samples with $95 \%$ accuracy*

\begin{tabular}{|c|c|c|c|c|}
\hline Operon Oligo ID & Description & Symbol & ENSEMBL/Refseq/Riken ID & Over/Under expressed in MS \\
\hline M400008627 & RIKEN cDNA 4921528107 gene & $4921528107 R i k$ & ENSMUSG00000074l49 & over \\
\hline$M 2000 I 2683$ & $\begin{array}{l}\text { Acetyl-Coenzyme A } \\
\text { acetyltransferase } 2\end{array}$ & Acat2 & ENSMUSG00000023832 & over \\
\hline M400004596 & $\begin{array}{l}\text { A disintegrin-like and } \\
\text { metalloprotease with } \\
\text { thrombospondin type I motif, } 9\end{array}$ & Adamts9 & ENSMUSG00000030022 & over \\
\hline M200000582 & Adenylate cyclase 8 & Adcy8 & ENSMUSG00000022376 & over \\
\hline M200005645 & $\begin{array}{l}\text { Actin related protein } 2 / 3 \text { complex, } \\
\text { subunit } 5 \text {-like }\end{array}$ & Arpc5I & ENSMUSG00000026755 & over \\
\hline M20000690I & $\begin{array}{l}\text { ATPase, } \mathrm{H}+\text { transporting, lysosomal } \\
\text { V0 subunit E2 }\end{array}$ & Atp6r0e2 & ENSMUSG00000039347 & over \\
\hline M400004024 & cDNA sequence $B C 013672$ & $B C 0 / 3672$ & ENSMUSG00000037921 & over \\
\hline M400008030 & $\begin{array}{l}\text { Bone gamma-carboxyglutamate } \\
\text { protein, related sequence I }\end{array}$ & Bglap-rs I & ENSMUSG00000074489 & over \\
\hline M3000II 602 & Carbonic anhydrase 14 & Carl4 & ENSMUSG00000038526 & over \\
\hline M200000995 & Cholecystokinins precursor & $C c k \S$ & ENSMUSG00000032532 & over \\
\hline$M 200013753$ & Coronin 7 & Coro7 & ENSMUSG00000039637 & over \\
\hline M200003934 & $\begin{array}{l}\text { Cytochrome P450, family } 2 \text {, } \\
\text { subfamily c, polypeptide } 29\end{array}$ & Сур2с29 & ENSMUSG00000003053 & over \\
\hline M3000I 3894 & RIKEN cDNA DI30054N24 gene & DI30054N24Rik & ENSMUSG00000042790 & over \\
\hline M400003995 & RIKEN cDNA D330050I23 gene & D330050123Rik & ENSMUSG00000072569 & over \\
\hline M3000I0488 & Dermokine & Dmkn & ENSMUSG00000060962 & over \\
\hline M200003607 & Dedicator of cytokinesis 7 & Dock7 & ENSMUSG00000028556 & over \\
\hline M3000I4949 & $\begin{array}{l}\text { Endothelial differentiation, } \\
\text { sphingolipid G-protein-coupled } \\
\text { receptor, } 5\end{array}$ & Edg5 & ENSMUSG00000043895 & over \\
\hline M40000I692 & Predicted gene & EG620592 & ENSMUSG00000071719 & over \\
\hline M4000I0593 & $\begin{array}{l}\text { Forkhead box protein RI } \\
\text { (Forkhead box protein N5) }\end{array}$ & Foxrl & ENSMUSG00000074397 & over \\
\hline M300000I32 & Homeo box A4 & Hoxa4 & ENSMUSG00000000942 & over \\
\hline M4000I3298 & LSMI 4 protein homolog A (Rap55) & Lsm / 4a & ENSMUSG00000066568 & over \\
\hline M40000482I & Lysocardiolipin acyltransferase & Lycat & ENSMUSG00000054469 & over \\
\hline M400009939 & $\begin{array}{l}\text { Mitogen-activated protein kinase } \\
\text { kinase kinase } 9\end{array}$ & Map3k9 & ENSMUSG00000042724 & over \\
\hline M300007290 & Mesoderm posterior 2 & Mesp2 & ENSMUSG00000030543 & over \\
\hline M200007I23 & Muted protein & Muted§ & ENSMUSG00000038982 & under \\
\hline M2000I0626 & Matrix-remodelling associated 8 & Mxra8 & ENSMUSG00000073679 & over \\
\hline M200007448 & $\begin{array}{l}\text { Nitric oxide synthase interacting } \\
\text { protein }\end{array}$ & Nosip & ENSMUSG0000000342I & over \\
\hline M3000I8063 & Olfactory receptor I495 & Olfr I 495 & ENSMUSG00000047207 & over \\
\hline M3000I7588 & Olfactory receptor 66 & Olfr66 & ENSMUSG00000058200 & over \\
\hline M3000I5973 & Olfactory receptor 669 & Olfr669 & ENSMUSG00000073916 & over \\
\hline M30000233I & Predicted gene & MGI:3652048 & ENSMUSG00000020682 & over \\
\hline M200003458 & Oxytocin & Oxt & ENSMUSG0000002730I & over \\
\hline M4000I0890 & $\begin{array}{l}\text { Mus musculus polymerase (RNA) II } \\
\text { (DNA directed) polypeptide C }\end{array}$ & Polr2c & ENSMUSG00000031783 & over \\
\hline M200000936 & Peripherin I & PrphI & ENSMUSG00000023484 & over \\
\hline M300003403 & PTK2 protein tyrosine kinase 2 & Ptk2 & ENSMUSG00000022607 & under \\
\hline M40000I722 & Slingshot homolog 3 (Drosophila) & Ssh3 & ENSMUSG00000034616 & over \\
\hline M300003482 & $\begin{array}{l}\text { Type } 2 \text { lactosamine alpha-2,3- } \\
\text { sialyltransferase }\end{array}$ & St3gal6§ & ENSMUSG00000022747 & under \\
\hline M200000227 & Stromal interaction molecule I & Stim I & ENSMUSG00000030987 & over \\
\hline$M 300001453$ & Surfeit gene 5 & Surf5 & ENSMUSG000000I 5776 & over \\
\hline M4000006I6 & Thrombopoietin precursor & Thpo & ENSMUSG00000022847 & over \\
\hline M400009774 & $\begin{array}{l}\text { Transmembrane BAX inhibitor motif } \\
\text { containing I }\end{array}$ & Tmbim I & ENSMUSG0000000630I & over \\
\hline M2000I3582 & Transmembrane protein 25 & Tmem 25 & ENSMUSG00000002032 & over \\
\hline M400000938 & Transmembrane protein $63 \mathrm{~A}$ & Tmem63a§ & ENSMUSG00000026519 & under \\
\hline
\end{tabular}


Table I: Summary of 50 gene predictor set, which classified samples with $\mathbf{9 5 \%}$ accuracy* (Continued)

\begin{tabular}{lllll}
\hline M400013169 & Xin actin-binding repeat containing 2 & Xirp2 & ENSMUSG00000027022 & over \\
isoform 2 & Zfp84 & ENSMUSG00000046185 & over \\
M400014435 & Zinc finger protein 84 & Not assigned & ACI60535 & over \\
M400018008 & Novel Protein & Not assigned & ACI21847 & over \\
M4000127II & Novel protein (1830077J02Rik) & Not assigned & AK054246 & over \\
M4000171I2 & Uncharacterised & Not assigned & ACI22270 & over \\
M4000037I2 & Uncharacterised & Not assigned & ENSMUSG00000064I59 & over \\
M400008575 & Uncharacterised & & & \\
\hline
\end{tabular}

*Genes are sorted by gene symbol; $\S$ Not included in differentially expressed gene list

A

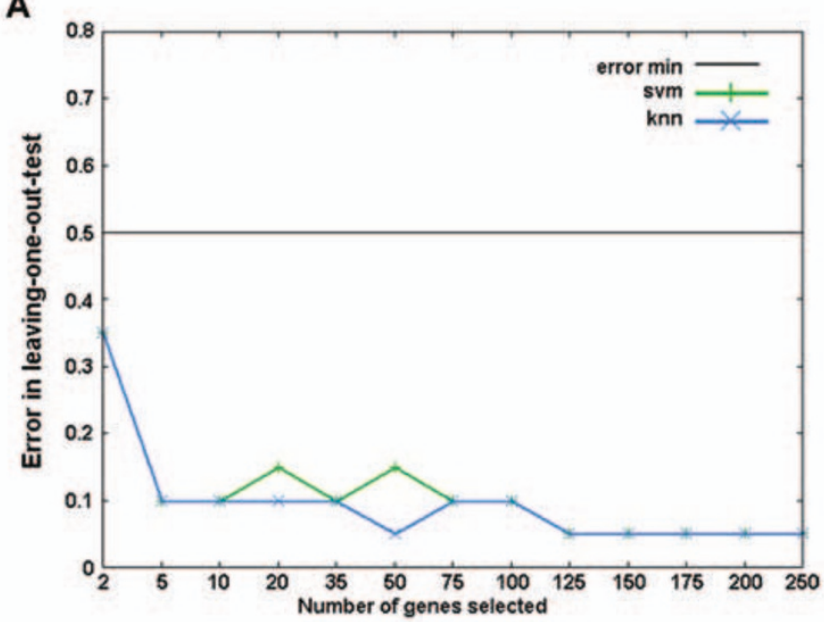

B

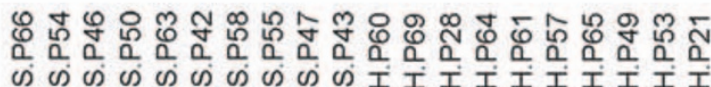
$\sum \sum \sum \sum \sum \sum \sum \sum \sum \sum \sum \sum \sum \frac{\omega}{\Sigma} \sum \sum \frac{T}{\omega} \frac{T}{\omega} \frac{T}{\omega} \frac{T}{\omega} \frac{T}{\omega} \frac{T}{\omega}$

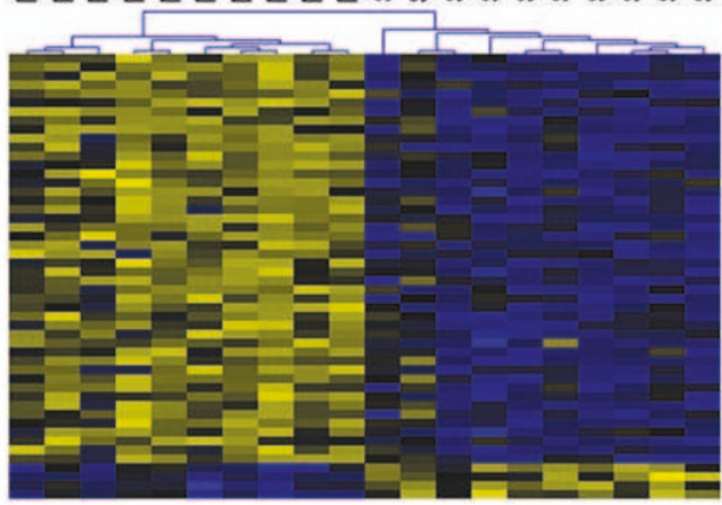

$-3.0$
C

\begin{tabular}{cccccc}
\hline & & \multicolumn{4}{c}{$\begin{array}{c}\text { Number of genes used I } \\
\text { Predicted Class }\end{array}$} \\
\cline { 3 - 6 } $\begin{array}{c}\text { ID } \\
\text { ID }\end{array}$ & Reas & $\mathbf{2}$ & 50 & 100 & 125 \\
\hline PBMC42 & MS & SH & MS & MS & MS \\
PBMC47 & MS & MS & MS & MS & MS \\
PBMC50 & MS & MS & MS & MS & MS \\
PBMC58 & MS & MS & MS & MS & MS \\
PBMC66 & MS & SH & MS & MS & MS \\
PBMC63 & MS & MS & MS & MS & MS \\
PBMC55 & MS & MS & MS & MS & MS \\
PBMC54 & MS & MS & MS & MS & MS \\
PBMC46 & MS & SH & MS & SH & MS \\
PBMC43 & MS & MS & MS & MS & MS \\
PBMC49 & SH & SH & SH & SH & SH \\
PBMC53 & SH & SH & SH & SH & SH \\
PBMC61 & SH & SH & SH & SH & SH \\
PBMC65 & SH & SH & SH & SH & SH \\
PBMC69 & SH & MS & MS & MS & MS \\
PBMC64 & SH & MS & SH & SH & SH \\
PBMC60 & SH & MS & SH & SH & SH \\
PBMC57 & SH & MS & SH & SH & SH \\
PBMC28 & SH & SH & SH & SH & SH \\
PBMC21 & SH & SH & SH & SH & SH \\
\hline
\end{tabular}

\section{Figure 5}

Sample classification and prediction results. (A) Leave-one-out error rates of classifiers. The KNN algorithm (blue line) reaches an optimal prediction efficiency of $95 \%$ with a minimum of 50 genes. Using 125 genes the SVM algorithm (green line) obtains this efficiency, and converges with KNN. (B) Hierarchically sample clustered (Pearson correlation metric with average linkage) profiles for the 50 gene predictor set. Notice, that although only 19 out of 20 samples were correctly classified, hierarchical clustering separates all samples into two general treatment-related clusters. (C) A summary of KNN sample classification results, showing details of the misclassification of individual samples. Although most samples classes were correctly predicted, PBMC69, an SH sample, was consistently misclassified. P = PBMC. 


\section{Additional material}

\section{Additional file 1}

Supplementary Methods. Detailed description of materials and methods, including a summary of RNA sample purity and integrity, and examples of box- and MA-plots from the PFC microarray dataset.

Click here for file

[http://www.biomedcentral.com/content/supplementary/17560500-2-195-S1.DOC]

\section{Additional file 2}

Table S2 Frontal Association Cortex differentially expressed genes. Summary of differentially expressed genes identified in frontal association cortex, including p-values for Info and SAM statistics, and $\log _{2}$ fold differences.

Click here for file

[http://www.biomedcentral.com/content/supplementary/17560500-2-195-S2.XLS]

\section{Additional file 3}

Table S3 Hippocampus differentially expressed genes. Summary of differentially expressed genes identified in hippocampus, including p-values for Info and SAM statistics, and $\log _{2}$ fold differences.

Click here for file

[http://www.biomedcentral.com/content/supplementary/17560500-2-195-S3.XLS]

\section{Additional file 4}

Table S4 Hypothalamus differentially expressed genes. Summary of differentially expressed genes identified in hypothalamus, including p-values for Info and SAM statistics, and $\log _{2}$ fold differences.

Click here for file

[http://www.biomedcentral.com/content/supplementary/17560500-2-195-S4.XLS]

\section{Additional file 5}

Table S5 Peripheral Blood Mononuclear Cells differentially expressed genes. Summary of differentially expressed genes identified in Peripheral Blood Mononuclear Cells, including p-values for Info and SAM statistics, and $\log _{2}$ fold differences.

Click here for file

[http://www.biomedcentral.com/content/supplementary/17560500-2-195-S5.XLS]

\section{Acknowledgements}

This work was supported by the following grants: a SA-Spain Collaboration Grant (UID 65229) held jointly by Dr Joaquin Dopazo (Bioinformatics Department, Centro de Investigación Principe Felipe, Valencia, Spain) and $\mathrm{NI}$, and a National Research Foundations (NRF) Grant (ICD200607 18000 I6) held by NI. JvH was a holder of a NRF Scarce Skills Scholarship. The National Institute of Bioinformatics http://www.inab.org is a platform of Genoma España.

\section{References}

I. Segman RH, Shefi N, Goltser-Dubner T, Friedman N, Kaminski N, Shalev AY: Peripheral blood mononuclear cell gene expression profiles identify emergent post-traumatic stress disorder among trauma survivors. Mol Psychiatry 2005 , I0(5):500-513.
2. Tsuang MT, Nossova N, Yager T, Tsuang MM, Guo SC, Shyu KG, Glatt SJ, Liew CC: Assessing the validity of blood-based gene expression profiles for the classification of schizophrenia and bipolar disorder: a preliminary report. Am J Med Genet B Neuropsychiatr Genet 2005, I 33B(I): I-5.

3. Besedovsky HO, del Rey A: Immune-neuro-endocrine interactions: facts and hypotheses. Endocr Rev 1996, I7(I):64-102.

4. Tang $Y$, Lu A, Aronow BJ, Sharp FR: Blood genomic responses differ after stroke, seizures, hypoglycemia, and hypoxia: blood genomic fingerprints of disease. Ann Neurol 200I, 50(6):699-707.

5. Meaney MJ, Szyf M: Maternal care as a model for experiencedependent chromatin plasticity? Trends in Neurosciences 2005, 28(9):456-463.

6. Romeo RD, Mueller A, Sisti HM, Ogawa S, McEwen BS, Brake WG: Anxiety and fear behaviors in adult male and female C57BL/ 6 mice are modulated by maternal separation. Horm Behav 2003, 43(5):56I-567.

7. Smyth GK: Limma: linear models for microarray data. In Bioinformatics and Computational Biology Solutions using $R$ and Bioconductor Edited by: Gentleman R, Carey V, Dudoit S, Irizarry R, Huber W. New York: Springer; 2005:397-420.

8. Nueda M, Conesa A, Westerhuis J, Hoefsloot H, Smilde A, Talon M, Ferrer $A$ : Discovering gene expression patterns in time course microarray experiments by ANAVO-SCA. Bioinformatics 2007, 23(14):8.

9. Guo L, Lobenhofer EK, Wang C, Shippy R, Harris SC, Zhang L, Mei $N$, Chen T, Herman D, Goodsaid FM, et al.: Rat toxicogenomic study reveals analytical consistency across microarray platforms. Nat Biotechnol 2006, 24(9): I I62-II69.

10. Tusher VG, Tibshirani R, Chu G: Significance analysis of microarrays applied to the ionizing radiation response. Proc Natl Acad Sci USA 200I, 98(9):5। 16-512I.

11. Conesa A, Gotz S, Garcia-Gomez JM, Terol J, Talon M, Robles M Blast2GO: a universal tool for annotation, visualization and analysis in functional genomics research. Bioinformatics 2005 , 2I( I 8):3674-3676.

12. Al-Shahrour F, Arbiza L, Dopazo H, Huerta-Cepas J, Minguez P, Montaner D, Dopazo J: From genes to functional classes in the study of biological systems. BMC Bioinformatics 2007, 8: I I4.

13. Medina I, Montaner D, Tarraga J, Dopazo J: Prophet, a web-based tool for class prediction using microarray data. Bioinformatics 2007, 23(3):390-391.

14. Sapolsky RM, Romero LM, Munck AU: How do glucocorticoids influence stress responses? Integrating permissive, suppressive, stimulatory, and preparative actions. Endocr Rev 2000, $2 I(I): 55-89$.

15. Olson R: GABA. In Neuropsychopharmacology: The Fifth Generation of Progress Edited by: Davis K, Charney D, Coyle J, Nemeroff C. Philadelphia: Lippincott, Williams \& Wilkins; 2002.

16. Wirkner K, Gunther A, Weber M, Guzman SJ, Krause T, Fuchs J, Koles L, Norenberg W, Illes P: Modulation of NMDA receptor current in layer $\mathbf{V}$ pyramidal neurons of the rat prefrontal cortex by P2Y receptor activation. Cereb Cortex 2007, I7(3):62I-63I

17. Jhamandas JH, Simonin F, Bourguignon J], Harris KH: Neuropeptide FF and neuropeptide VF inhibit GABAergic neurotransmission in parvocellular neurons of the rat hypothalamic paraventricular nucleus. Am J Physiol Regul Integr Comp Physiol 2007, 292(5):RI872-1880.

18. Osterweil E, Wells DG, Mooseker MS: A role for myosin VI in postsynaptic structure and glutamate receptor endocytosis. Journal of Cell Biology 2005, 168(2):329-338.

19. Puig MV, Santana N, Celada P, Mengod G, Artigas F: In vivo excitation of GABA interneurons in the medial prefrontal cortex through 5-HT3 receptors. Cereb Cortex 2004, I 4( I 2): I 365- I 375.

20. Crestani F, Lorez M, Baer K, Essrich C, Benke D, Laurent JP, Belzung C, Fritschy JM, Luscher B, Mohler H: Decreased GABAA-receptor clustering results in enhanced anxiety and a bias for threat cues. Nat Neurosci 1999, 2(9):833-839.

2I. Vassilaki A, Lanneau C, Dournand P, de Lecea L, Gardette R, Epelbaum J: Cortistatin affects glutamate sensitivity in mouse hypothalamic neurons through activation of somatostatin receptor subtype. Neuroscience 1999, 88(2):359-364.

22. Moghaddam B: Stress activation of glutamate neurotransmission in the prefrontal cortex: implications for dopamine- 
associated psychiatric disorders. Biological Psychiatry 2002, 5 I:775-787.

23. Kasprowicz DJ, Smallwood PS, Tyznik AJ, Ziegler SF: Scurfin (FoxP3) controls T-dependent immune responses in vivo through regulation of CD4+ T cell effector function. J Immunol 2003, I7I(3): $1216-1223$.

24. Gaffen SL: An overview of IL-I 7 function and signaling. Cytokine 2008, 43(3):402-407.

25. Grayson MH, Holtzman MJ: Chemokine complexity: the case for CCL5. Am J Respir Cell Mol Biol 2006, 35(2): I 43-I46.

26. Ring R, Malberg J, Potestio L, Ping J, Boikess S, Luo B, Schechter L, Rizzo S, Rahman Z, Rosenzweig-Lipson S: Anxiolytic-like activity of oxytocin in male mice: behavioral and autonomic evidence, therapeutic implications. Psychopharmacology 2006, 185(2):218-225.

27. Schaefer ML, Wong ST, Wozniak DF, Muglia LM, Liauw JA, Zhuo M, Nardi A, Hartman RE, Vogt SK, Luedke CE, et al:: Altered stressinduced anxiety in adenylyl cyclase type VIII-deficient mice. J Neurosci 2000, 20(13):4809-4820.

28. Windle RJ, Shanks N, Lightman SL, Ingram CD: Central oxytocin administration reduces stress-induced corticosterone release and anxiety behavior in rats. Endocrinology 1997, I 38(7):2829-2834.

29. Csaba G, Pallinger E: In vitro effect of hormones on the hormone content of rat peritoneal and thymic cells. Is there an endocrine network inside the immune system? Inflamm Res 2007, 56(I I):447-45I.

30. Meng AH, Ling YL, Zhang XP, Zhang JL: Anti-inflammatory effect of cholecystokinin and its signal transduction mechanism in endotoxic shock rat. World J Gastroenterol 2002, 8(4):7| 2-7|7.

Publish with Bio Med Central and every scientist can read your work free of charge

"BioMed Central will be the most significant development for disseminating the results of biomedical research in our lifetime. "

Sir Paul Nurse, Cancer Research UK

Your research papers will be:

- available free of charge to the entire biomedical community

- peer reviewed and published immediately upon acceptance

- cited in PubMed and archived on PubMed Central

- yours - you keep the copyright 